\title{
PENGGUNAAN KAPPA CARAGENAN SEBAGAI BAHAN PENGENKAPSULASI Lactobacillus acidophilus TERHADAP VIABILITAS DAN "Shelflife"
}

\author{
Dwi Setijawati* \\ Fakultas Perikanan dan Ilmu Kelautan, Universitas Brawijaya \\ Jl.Veteran 65145 Malang, Indonesia \\ *Koresponden penulis : dwisetyawati@ub.ac.id
}

\begin{abstract}
Abstrak
Tujuan penelitian adalah mencari pengaruh penggunaan kappa caragenan sebagai bahan pengenkapsulasi Lactobacillus acidophilus terhadap viabilitas dan shelflife. Metode penelitian adalah laboratorium eksperimental desain dengan Rancangan Acak Lengkap (RAL), ANOVA, dilanjutkan dengan uji Fisher,s untuk menguji perbedaan. Analisa data menggunakanMinitab 16 software. Perlakuan penelitian adalah konsentrasi kappa caragenan dengan sub perlakuan sebagai berikut : A1 (2\%);A2 (2,5\%);A3 (3,0\%);A4 (3,5\%);A5 (4,0\%);A6(4,5\%).Hasil penelitian menunjukkan bahwa penggunaan kappa caragenan dengan konsentrasi berbeda sebagai bahan pengenkapsulasi Lactobacillus acidophilus memberikan pengaruh berbeda sangat nyata terhadap viabilitas Lactobacillus acidophilus dan yield enkapsulasi. Viabilitas meningkat seiring dengan peningkatan konsentrasi kappa caragenan yang digunakan. Viabilitas tertinggi sebesar $8.71 \log \mathrm{CFu} / \mathrm{mL}$ didapatkan dengan menggunakan konsentrasi kappa caragenan 4,5\% dengan perhitungan Shelflife sebesar 65,73 tahun penyimpanan pada suhu $5^{\circ} \mathrm{C}$. Saran penelitian adalah pengujian mikrokapsul Lactobacillus acidophilus yang terenkapsulasi kappa caragenan 4,5\% pada larutan simulasi GI Tract.
\end{abstract}

Kata Kunci : Eucheuma cottonii, mikroenkapsulasi, emulsifikasi

\begin{abstract}
The aim of the study was to find out the effect of using kappa caragenan as an Lactobacillus acidophilus encapsulating material on viability and "shelflife". The research method was an experimental laboratory design with Completely Randomized Design (CRD), ANOVA, followed by the Fisher test, to test for differences. Data analysis using Minitab 16 software. The research treatment was the concentration of kappa caragenan with sub-treatment as follows: A1 (2\%); A2 (2.5\%); A3 (3.0\%); A4 (3.5\%); A5 (4.0\%); A6 (4.5\%) The results showed that the use of different concentrations of kappa caragenan as an encapsulation material for Lactobacillus acidophilus had a very significant difference effect on the viability of Lactobacillus acidophilus and encapsulation yield. Viability increases with increasing concentration of kappa caragenan used. The highest viability of $8.71 \log C F u / m L$ was obtained using a $4.5 \%$ kappa caragenan concentration with a "Shelflife" calculation of 65.73 years of storage at $5^{\circ} C$. The research suggestion was testing $4.5 \%$ Lactobacillus acidophilus microcapsules encapsulated by kappa carrageenan in GI Tract simulation solution.
\end{abstract}

Keywords: Eucheuma cottonii, Microencapsulation, Emulsification

\section{PENDAHULUAN}

Pemanfaatan Eucheuma sp dengan hasil ekstrak caragenan beserta sifat fungsionalnya dapat digunakan sebagai bahan pengenkapsulat pada proses mikroenkapsulasi. Kemampuan caragenan untuk membentuk gel dapat dimanfaatkan sebagai media pengenkapsulat seperti mengkapsul bakteri probiotik atau bakteri asam laktat. Miroenkapsulasi Lactobacillus bulgaricus dengan menggunakan bahan caragenan dan Locust Bean Gum sudah dilakukan dan menghasilkan viabilitas sebesar [1]. Caragenan dapat dihasilkan melalui ekstraksi kelompok Rhodophyceae red hidrokoloid seperti Eucheuma sp, Chondrus sp dan Irish Moss.

Hasil ekstraksi rumput laut merah dengan menggunakan air panas (hot water) 
atau larutan alkali pada suhu tinggi akan menghasilkan Caragenan yang memiliki polisakarida linier dan berat molekul yang terdiri atas 1000 lebih residu galaktosa yaitu ester, kalium, natrium dan kalium sulfat dengan galaktosa dan 3,6 anhydrogalaktokopolimer. Eucheuma cottonii penghasil caragenan tipe kappa. Sifat gel kappa caragenan adalah kuat, mudah patah dan sineresis. Pemilihan bahan pengenkapsulat merupakan kriteria penting untuk menentukan tujuan penggunaan teknologi mikroenkapsulasi untuk meningkatkan viabilitas atau "shelflife" dan menjamin kemampuan "controle and release" yang sesuai dengan target. Mikroenkapsulasi probiotik seperti $L$ acidophilus. Dimana $L$ acidophilus adalah salah satu spesies bakteri probiotik yang termasuk dalam genus Lactobacillus. Sel probiotik harus hidup saat dikonsumsi dan mencapai target mempertahankan viabilitas dan stabilitas mencapai jumlah yang memadai yaitu sebesar $1 \times 10^{7}$ colony-forming unit (cfu) $/ \mathrm{ml}$. Menurut [2], hasil enkapsulasi menggunakan whey protein yang digunakan bahan pengenkapsulat dapat digunakan untuk memperkirakan jumlah sel awal Lactobacillus sp serta memperkirakan waktu simpan sampai bakteri tersebut tidak bermanfaat lagi, karena seluruh sel telah mati. Sehingga penelitian mengenai $L$. acidophilus yang terenkapsulasi caragenan dengan konsentrasi berbeda terhadap viabilitas dan daya simpan (shelf life) sel perlu penelitian mengenai hal tersebut.

\section{MATERI DAN METODE PENELITIAN}

\section{Bahan penelitian dan Alat penelitian}

Bahan utama yang digunakan dalam penelitian ini adalah kappa caragenan dan maltodekstrin. Bahan tambahan lain untuk proses analisis antara lain : $\mathrm{KOH}$ teknis, $\mathrm{KCL}$ teknis, MRS-Agar dan $\mathrm{NaCl}$. Alat yang digunakan terdiri dari Laminar Air Flow, stirrer incubator, vortex mixer, spektrofotometer Infra red Shimizu model IR-430, tensile strength instrument merek Imada/ZP-200 N, Viscometer Brookfield.

\section{Metode penelitian}

Metode penelitian yang digunakan adalah metode laboratorium eksperimental desain dengan menggunakan rancangan Acak lengkap, yang dianalisa dengan Analysis of Variance (ANOVA) untuk mengetahui pengaruh, kemudian dilanjutkan dengan uji Fisher,s Test untuk mengetahui perbedaan diantara perlakuan. Analisa uji dilakukan dengan SPSS 16 Software. Perlakuan konsentrasi bahan pengenkapsulasi sebagai variable bebas dengan sub level perlakuan terdiri dari : A1 (2\%); A2 $(2,5 \%)$ ;A3 (3,0\%); A4 (3,5\%); A5 (4,0\%); A6 $(4,5 \%)$. Analisa dilanjutkan dengan pengujian normalitas menggunakan metode Kolmogorov-Smirnov, analisis sidik ragam (ANOVA), uji Fisher,s.Analisa menggunakan Minitab 16 software.

\section{a) Pembuatan kappa caragenan dengan metoda PNG (Philipine Natural Grade) [3]}

Rumput laut E. cottonii yang diambil dari Madura Kep, Indonesia.dicuci kemudian dikeringkan. Tahapan dalam pembuatan kappa caragenan dari rumput laut E. cottonii menggunakan metode PNG (Philipine Natural Grade), melalui langkah sebagai berikut: Rumput laut E. cottonii kering dicuci sampai bersih masing-masing ditimbang sebanyak 25 gram. Rumput laut yang sudah ditimbang kemudian ditambah air dan $\mathrm{KOH}$ $6 \%$. Kemudian dipanaskan dengan suhu \pm $70^{\circ} \mathrm{C}$ selama \pm 120 menit. Setelah itu diangkat dan dinetralkan dengan air sampai $\mathrm{pH}$ netral, kemudian dipotong-potong dengan ukuran 3-5 cm, dijemur, setelah kering dihaluskan dengan blender.

\section{b) Pembuatan mikrokapsul Lactobacillus acidophilus dengan kappa caragenan dari ekstraksi Eucheuma cottonii}

Pembuatan mikroenkapsulasi $L$. acidophilus dari kappa caragenan [4] yang sudah dilakukan modifikasi melalui langkah langkah sebagai berikut :Pertama tama sol caragenan disiapkan kemudian dipanaskan pada suhu $\pm 96^{\circ} \mathrm{C}$ selama \pm 5-6 menit setelah itu suhu diturunkan dan diatur pada suhu \pm $40-45^{\circ} \mathrm{C}$. Kemudian sol caragenan yang telah 
dipanaskan kemudian dimasukan ke dalam suspensi bakteri sebanyak $10 \mathrm{~mL}$. Pekerjaan selanjutnya adalah tahapan persiapan pembuatan emulsi. Emulsi dibuat dari pencampuran $50 \mathrm{~mL}$ minyak sayur (mengandung 0,1\% tween 80).Minyak sayur yang telah disiapkan kemudian diaduk dengan stirrer hotplate pada suhu $\pm 40^{\circ} \mathrm{C}$ selama $\pm 2-3$ menit. Tahap selanjutnya adalah sol kappa caragenan dan sel ditambahkan ke dalam emulsi berupa minyak sayur sebagai pengemulsi. Hasil percampuran kemudian distirrer hotplate selama \pm 10 menit dengan kecepatan 500 rpm lalu ditambah $75 \mathrm{~mL} \quad \mathrm{KCl} 3,9 \mathrm{M}$ sehingga diperoleh fase minyak dan kapsul. Fase minyak dipisahkan dari kapsul dan disentrifus dengan kecepatan $875 \mathrm{rpm}$ selama \pm 10 menit. Kapsul dicuci sebanyak 2 kali menggunakan $\mathrm{KCl}$ 3,9 $\mathrm{M}$ dengan sentrifugasi yang sama kemudian disimpan pada suhu \pm $4,4^{\circ} \mathrm{C}$ sehingga diperoleh mikroenkapsulat.

\section{c) Pengujian viskositas bahan kappa caragenan dari ekstraksi Eucheuma cottonii}

Pengujian larutan caragenan dengan konsentrasi $1,5 \%$ dipanaskan dalam air mendidih sambil diaduk secara teratur sampai suhu mencapai $75^{\circ} \mathrm{C}$. Viskositas diukur dengan Viscometer Brookfield. Spindel terlebih dahulu dipanaskan pada suhu $75^{\circ} \mathrm{C}$ kemudian dipasang ke alat ukur Viscometer Brookfield. Posisi spindel dalam larutan panas diatur sampai tepat, viskometer dihidupkan dan suhu larutan diukur. Ketika suhu larutan mencapai $75^{\circ} \mathrm{C}$ dan nilai viskositas diketahui dengan pembacaan viskometer pada skala 1 sampai 100. Pembacaan dilakukan setelah satu menit putaran penuh 2 kali untuk spindel no 1 .

\section{d) Pengujian Gel kappa caragenan dari ekstraksi Eucheuma cottonii}

Prosedur pengujian melalui langkah kappa Caragenan dan maltodekstrin masingmasing 1,6\% dipanaskan dalam air mendidih dengan volume larutan $50 \mathrm{~mL}$ dan diaduk secara teratur sampai suhu $80^{\circ} \mathrm{C}$, kemudian diletakkan sampel pada tensile strength instrument dengan merek Imada/ZP-200 N, spesifikasi digital force gauge dengan tegangan $220 \mathrm{~V}-240 \mathrm{~V}$, kemudian di ON kan sehingga komputer secara otomatis akan mencatat gaya $(\mathrm{N})$ dan jarak yang ditempuh oleh tekanan atau tarikan terhadap sampel.

e) Pengujian kappa caragenan dari ekstraksi Eucheuma cottonii menggunakan Fourier Transform Infrared Spectrometer (FT-IR)

Pengujian FT-IR ini dilakukan untuk mengetahui gugus fungsional dari kappamaltodekstrin. Adapun prinsip pengujian FTIR adalah absorbsi gugus karbonil menggunakan serapan inframerah. Pengukuran absorbsi radiasi infrared pada berbagai panjang gelombang dilakukan dengan spektrofotometer Infra red Shimizu model IR-430.

\section{f) Pengujian Viabilitas Lactobacillus acidophilus}

Prosedur kerja dari analisis viabilitas $L$. acidophillus adalah sebagai berikut : Mikrokapsul diambil sebanyak $0,1 \mathrm{~g}$. Dimasukan ke dalam $10 \mathrm{~mL}$ larutan NaFis. Dihomogenkan menggunakan vortex mixer selama 10 menit. Dilakukan pengenceran bertingkat dan dilakukan penenaman dengan metode tuang dalam media MRS-Agar. Diinkubasi dalam kondisi anerob pada inkubator dengan suhu $37^{\circ} \mathrm{C}$ selama 48 jam. Dilakukan perhitungan viabilitas bakteri menggunakan metode perhitungan Total Plate Count (TPC) dalam satuan $\log$ $\mathrm{CFU} / \mathrm{mL}$.

\section{Pengujian Yield Enkapsulasi}

Yield enkapsulasi menurut [5] merupakan efisiensi dari penyalut dengan jumlah bakteri yang mampu untuk bertahan hidup setelah proses enkapsulasi dihitung sebagai Encapsulation Yield (EY). Rumus untuk menghitung yield enkapsulasi adalh sebagai berikut :

$\mathrm{EY}=\mathrm{N} / \mathrm{N} 0$

Keterangan :

$\mathrm{N}$ = Jumlah sel hidup setelah proses pengeringan.

$\mathrm{N}_{0}=$ Jumlah sel hidup yang ditambahkan (kepadatan awal) 
g) Pengujian "Shelflife" Lactobacillus acidophilus yang terenkapsulasi kappa caragenan

Viabilitas Lactobacillus acidophilus dan struktur mikroenkapsulat pada masa simpan 14 hari $5^{\circ} \mathrm{C}$ dan $37^{\circ} \mathrm{C}$, uji waktu simpan sel terenkapsulat menggunakan persamaan :

$$
\mathrm{T}=\frac{8 \log \mathrm{S}_{\mathrm{o}}}{\log \mathrm{S}_{\mathrm{o}}-\mathrm{S}_{\mathrm{ac}}}
$$

Dimana:

$S_{o}=$ viabilitas pada saat nol hari atau segera dihitung viabilitas setelah proses enkapsulasi

$\mathrm{S}_{\mathrm{ac}}=$ survival rate setelah disimpan selama 14 hari pada suhu optimal pertumbuhan sel.

$\mathrm{T}=$ masa simpan sel terenkapsulat.

\section{HASIL DAN PEMBAHASAN}

\section{Karakteristik Kappa caragenan dari ekstraksi Eucheuma cottonii}

Hasil ekstraksi didapatkan kappa caragenan. Penentuan kappa caragenan dapat diamati berdasarkan gugus fungsi pada bilangan gelombang. Penentuan gugus fungsi berdasarkan bilangan gelombang menggunakan FTIR dapat dilihat pada Gambar 1.

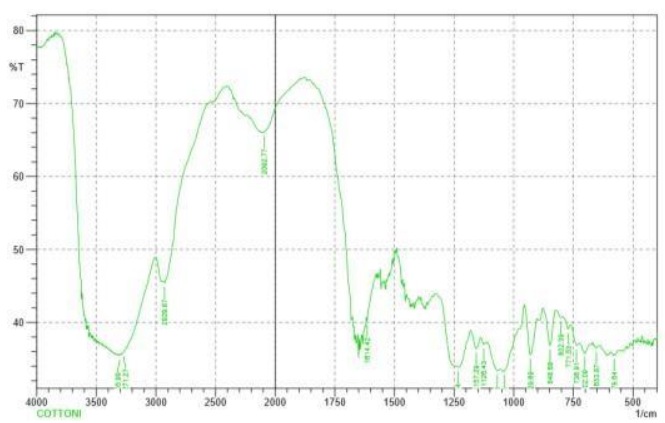

Gambar 1. Gugus fungsi kappa caragenan yang diekstraksi dari Eucheuma cottonii menggunakan FTIR
Tabel 1. Bilangan gelombang gugus fungsi kappa caragenan yang diekstraksi dari Eucheuma cottonii menggunakan FTIR dibandingkan dengan standar

\begin{tabular}{lcc}
\hline & \multicolumn{2}{c}{ Bilangan Gelombang } \\
\cline { 2 - 2 } & Kappa $(*)$ & Kappa (**) \\
\hline Ester Sulfat & 1261,8 & 1258 \\
Ikatan Glikosidik & 1068,7 & 1070 \\
$\quad 3,6$ AG & 929,8 & 937,7 \\
D-galaktan-4SO4 & 844,9 & 847,7 \\
D-galaktan-2SO4 & - & - \\
D-gal-6S & - & - \\
3.6-AG-2SO4 & 802,5 & - \\
\hline
\end{tabular}

Keterangan : $(*)$ standar

(**) hasil penelitian

Hasil penelitian yang diamati pada Gambar serta tersaji pada Tabel menunjukkan intensitas serapan yang ditunjukkan oleh ester sulfat, ikatan glikosidik dan galaktosa sangat kuat yang diamati bedasarkan bilangan gelombang. Caragenan ditandai dengan dengan gugus fungsi ester sulfat yang terdapat pada bilangan gelombang 1210-1260 cm-1, ikatan glikosidik pada 1010-1080 cm-1. AnhidroGalaktosa (AG) pada 928-933 cm-1, galaktosa sulfat pada $840-850 \mathrm{~cm}-1$, dan galaktosa 2 sulfat pada $800-805 \quad \mathrm{~cm}-1$. Intensitas serapan yang diyunjukkan oleh ester sulfat, ikatan glikosidik dan galaktosa sangat kuat. Eucheuma cottonii mengandung kappa caragenan yang tersusun dari $(1,3) \mathrm{D}$ Galaktosa-4-sulfat dan (1,4)-3,6-Anhidro-DGalaktosa. Sehingga dapat disimpulkan bahwa bahan Eucheuma cottonii Bahan yang digunakan dalam penelitian adalah Eucheuma cottonii yang dipanen dari daerah Lombok Kep, Indonesia dengan metoda ekstraksi menggunakan alkali. adalah penghasil kappa caragenan.

\section{Karakteristik Fisikokimia Kappa Caragenan yang diekstraksi dari Eucheuma cottonii}

Karakteristik fisikokimia Kappa Caragenan yang diekstraksi dari Eucheuma cottonii dapat dilihat pada Tabel 2. 
Tabel 2. Karaketristik Fisikokimia Kappa Caragenan konsentrasi 4,5\%

\begin{tabular}{ll}
\hline & $\begin{array}{c}\text { Kappa caragenan dari } \\
\text { ekstraksi Eucheuma } \\
\text { cottonii }\end{array}$ \\
\hline Kadar Air (\%) & $12 \%$ \\
Gel Strength (N) & $4,9 \mathrm{~N}$ \\
Viskositas $(\mathrm{Cps})$ & 825 \\
Gelling Point $\left({ }^{\circ} \mathrm{C}\right)$ & $25,2{ }^{\circ} \mathrm{C}$ \\
Melting Point $\left({ }^{\circ} \mathrm{C}\right)$ & $82{ }^{\circ} \mathrm{C}$ \\
\hline
\end{tabular}

Proses pembuatan kappa caragenan dengan metoda PNG merupakan salah satu cara dalam meningkatkan kekuatan gel caragenan. Penggunaan larutan alkali pada suhu proses $75-80{ }^{\circ} \mathrm{C}$ adalah dalam rangka pemutusan gugus ester sulfat menjadi gugus 3,6 AG. Adanya gugus 3,6 AG dapat mempengaruhi kekuatan gel. Kekuatan gel dapat meningkat seiring dengan peningkatan konsentrasi. Kemampuan membentuk gel pada kappa caragenan merupakan faktor dalam pembentukan beads mikrokapsul.

\section{Pengaruh Perlakuan konsentrasi Kappa Caragenan Terhadap viabilitas Lactobacillus acidophilus.}

Pengaruh perlakuan kappa caragenan dengan konsentrasi berbeda terhadap viabilitas Lactobacillus acidophilus dan yield enkapsulasi ditunjukkan pada Tabel 3.

Tabel 3. Pengaruh perlakuan kappa caragenan dengan konsentrasi berbeda terhadap viabilitas Lactobacillus acidophilus dan yield enkapsulasi

\begin{tabular}{cccc}
\hline \multirow{2}{*}{ Perlakuan } & $\begin{array}{c}\text { Viabilitas log } \\
\text { Cfu/mL }\end{array}$ & & $\begin{array}{c}\text { Yield } \\
\text { enkapsulasi (\%) }\end{array}$ \\
\cline { 2 - 2 } A1 & $6.43 \pm 0,05 \mathrm{~d}$ & & $71.44 \pm 0,56 \mathrm{a}$ \\
A2 & $6.71 \pm 0,09 \mathrm{c}$ & & $74.59 \pm 1,03 \mathrm{a}$ \\
A3 & $7.52 \pm 0,13 \mathrm{~b}$ & & $83.63 \pm 1,51 \mathrm{~b}$ \\
A4 & $7.61 \pm 0,06 \mathrm{~b}$ & & $84,62 \pm 0,71 \mathrm{~b}$ \\
A5 & $8.67 \pm 0,05 \mathrm{a}$ & & $93.62 \pm 0,55 \mathrm{c}$ \\
A6 & $\underline{8.71 \pm 0,02 \mathrm{a}}$ & & $97.73 \pm 0,23 \mathrm{~d}$ \\
\hline
\end{tabular}

Keterangan : rata-rata dengan notasi yang sama menunjukkan tidak berbeda nyata

Dari hasil penelitian yang diamati melalui Tabel 2 didapatkan bahwa semakin meningkat konsentrasi bahan pengenkapsulasi, maka viabilitas bakteri Lactobaciluus acidophilus juga semakin meningkat serta yield enkapsulasi juga semakin besar. Hal ini disebabkan karena peningkatan derajad keseragaman molekul kappa caragenan yang meningkat dan diikuti dengan daya gelasi yang juga meningkat. Daya gelasi meningkat seiring dengan peningkatan konsentrasi. Konsentrasi bahan meningkat menyebabkan sistim gelasi meningkat maka pembentukan wall atau dinding mikrokapsul akan semakin tebal. Ketebalan dinding mikrokapsul yang semakin tebal dapat meningkatkan daya perlindungan terhadap isi atau bakteri didalamnya. Ketebalan dinding akan diikuti dengan kerapatan matriks dinding mikrokapsul sehingga dapat mempeertahankan bakteri dari tekanan eksternal seperti suhu, $\mathrm{pH}$, oksigen serta tahapan dalam proses pembuatan mikrokapsul.

Hal ini sejalan dengan pendapat [6] bahwa Kappa caragenan tersusun dari $(1,3)$ D-galaktosa-4-sulfat dan (1,4)-3,6-anhidroD-galaktosa dan mempunyai D-galaktosa-6sulfat ester dan 3,6-anhidro-D-galaktosa-2sulfat ester. pemberian alkali seperti $\mathrm{K}+$ dalam proses ekstraksinya akan terjadi pergantian atau pemutusan gugusan 6-sulfat, sehingga menghasilkan 3,6-anhidro-Dgalaktosa.

Adanya gugusan 6-sulfat, dapat menurunkan daya gelasi dari caragenan. Sedangkan hubungan daya gelasi dengan peningkatan viabilitas adalah pengkerasan butiran atau pembentukan droplets didalam fase minyak pada proses pembuatan mikrokapsul sangat tergantung dengan kekuatan gel dan viskositas bahan pengenkapsulasi. Pengkerasan pada kulit bagian luar mikrokapsul terjadi secara cepat, ketika berkontak dengan bahan atau larutan pengkeras atau penstabil yaitu ketika ion $\mathrm{Ca} 2+$ atau $\mathrm{K}+$ merembes masuk dalam rangka meningkatkan ketebalan layer alginate dan mengeraskannya. Stabilitas meningkat seiring dengan peningkatan konsentrasinya.

Penentuan " Shelflife" Lactobacillus acidophilus yang terenkapsulasi Kappa Caragenan dari hasil perlakuan terbaik

Penentuan "Shelflife" Lactobacillus acidophilus yang terenkapsulasi Kappa Caragenan yang diekstraksi dari Eucheuma cottonii mengunakan rumus Sakane Dan Kuroshima didapatkan 65,43 tahun pada suhu 
penyimpanan $5^{\circ} \mathrm{C}$. Sehingga "Shelflife" bakteri Lactobacillus acidophilus yang ternkapsulasi kappa caragenan yang diekstraksi dari rumput laut Eucheuma cottonii dengan menggunakan metode Emulsifikasi adalah 65,79 tahun sampai bakteri tersebut tidak bisa digunakan dan kehilangan viabilitasnya.

\section{KESIMPULAN}

Penggunaan Kappa Caragenan dengan konsentrasi berbeda sebagai bahan enkapsulasi Lactobacillus acidophilus memberikan pengaruh berbeda sangat nyata terhadap viabilitasnya dan yield enkapsulasi. Semakin tinggi penggunaan konsentrasi Kappa Caragenan memberikan hasil yang semakin meningkat pada viabilitas Lactobacillus acidophilus dan yield enkapsulasi. Viabilitas Lactobacillus acidophilus dan yield enkapsulasi tertinggi didapatkan pada perlakuan A6 yaitu penggunaan konsentrasi 4,5\% viabilitas sebesar 8,71 Log Cfu/mL dan yield sebesar 97,73\% dengan perhitungan "Shelflife" pada suhu penyimpanan $5^{\circ} \mathrm{C}$ sebesar 65,79 tahun.

\section{SARAN}

Konsentrasi 4,5\% Kappa Caragenan yang diekstraksi dari Eucheuma cottonii memberikan viabilitas Lactobacillus acidophilus yang memenuhi standar WHO sebesar $10^{7} \mathrm{Cfu} / \mathrm{mL}$.Akan tetapi perlu dilakukan penelitian tentang viabilitas Lactobacillus acidophilus setelah melewati pH GI Tract sebagai indicator keberhasilan proses mikroenkapsulasi Lactobacillus acidophilus.

\section{UCAPAN TERIMA KASIH}

Ucapan terima kasih disampaikan kepada Institusi Fakultas Perikanan Dan Ilmu Kelautan Universitas Brawijaya Malang yang telah memberikan dukungan dana bagi terselesaikan penelitian ini.

\section{DAFTAR PUSTAKA}

[1] Shi, L.-E., Li, Z.-H., Zhang, Z.-L., Zhang, T.-T., Yu, W.-M., Zhou, M.-L., \& Tang, Z.-X. (2013). Encapsulation of
Lactobacillus bulgaricus in carrageenanlocust bean gum coated milk microspheres with double layer structure. LWT - Food Science and Technology, 54(1), 147-151. https://doi.org/10.1016/j.lwt.2013.05.027

[2] Triana, E. E, Yulianto. N, Nurhidayat. 2006. Uji Viabilitas Lactobacillus $s p$. Mar 8 Terenkapsulasi. Lembaga Ilmu Pengetahuan Indonesia (LIPI). Bogor. Halaman 114-117.

[3] Setijawati, D., S. Wijana, dan I. Santosa. 2011. "Viabilitas Dan Struktur Mikrokapsul Lactobacillus acidophillus Dengan Bahan Penyalut Karaginan Semi Murni Jenis Eucheuma cottoni." Jurnal Teknologi Pangan 2 (1): 50-67.

[4] Adhikari. K, Mustapha A, and L.U Grun, 2003. Survival and Metabolic Activity of Microencapsulated Bifidobacterium longum in stirred Yogurt.

[5] Chavarri, M., Maranon, I., Ares, R., Ibanez, F. C., Marzo, F., \& Villarán, M. D. C. 2010. Microencapsulation of a probiotic and prebiotic in alginatechitosan capsules improves survival in simulated gastro-intestinal conditions. International Journal of Food Microbiology, 142(1-2), 185-9

[6] Winarno, 1996. Teknologi Pengolahan Rumput Laut. Jakarta: Pustaka Sinar Harapan 